\title{
Liberalismo y pretensiones científicas en Noticias estadisticas del estado de Sonora
}

\author{
Liberalism and Scientific Pretensions in 'Noticias estadísticas \\ del estado de Sonora'
}

Selene Quiroz Moreno

EL COLEGIO DE SONORA, selene_quiroz@hotmail.com

\author{
Zulema Trejo \\ EL COLEGIO DE SONORA, ztrejo@colson.edu.mx
}

Se analiza la obra de José Francisco Velasco Noticias estadísticas del estado de Sonora (1850), identificando los elementos del utilitarismo decimonónico propio del liberalismo, que se presentaban principalmente como propuestas de tipo económico-administrativo; se rescatan también las pretensiones de cientificidad presentes en el trabajo, elaborado desde la perspectiva de la estadística descriptiva. Se destaca la importancia del autor y de su obra por el momento histórico en que fue elaborada, de consolidación de las instituciones y de la ciencia como generadora de información útil para los gobiernos.

PALABRAS CLAVE: liberalismo, ciencia, estadística, gobierno, utilitarismo.

This study analyzes José Francisco Velasco's work, Noticias estadísticas del estado de Sonora (1850), to identify the elements of $19^{\text {th }}$-century utilitarianism that were typical of liberalism, presented primarily as economic-administrative proposals. It also rescues the book's pretensions to a scientificity elaborated on the basis of the perspective of descriptive statistics, while emphasizing the importance of the author and the book in relation to the historical moment in which it was elaborated, the consolidation of institutions, and the role of science as a generator of information useful for governments.

KEYWORDS: liberalism, science, statistics, government, utilitarianism.

Fecha de recepción del artículo: 21 de marzo de 2015 / Fecha de aprobación: 5 de agosto de 2015 / Fecha de recepción de la versión final: 14 de octubre de 2015

\section{INTRODUCCIÓN}

lo largo del siglo xix se elaboraron una serie de trabajos des-
criptivos referentes a una o varias partes de la república
mexicana; estos textos tenían una estructura similar ya que 
también un apartado para dar a conocer como estaba estructurado el gobierno de dicha región. Estos documentos reciben el nombre genérico de memorias o memorias estadísticas. Como ejemplos podemos citar las siguientes: La huasteca potosina. Ligeros apuntes sobre este país; Estadistica del estado de Querétaro (1854-1855); Noticias estadisticas del estado de Chihuahua; Noticias estadisticas de Sonora y Sinaloa; Análisis estadístico de la provincia de Michoacán entre otros.

Sonora, al igual que otros lugares del país, fue objeto de interés para los hombres ilustrados del siglo XIX, quienes indagaron y escribieron acerca de cuestiones como el número de habitantes, la situación geográfica, la administración pública, etcétera; el resultado de esos estudios se plasmó en obras que se catalogan en el género memorias estadísticas, algunas de las más conocidas en la historiografía sonorense son Rápida ojeada al estado de Sonora de Ignacio Zúñiga; Noticias estadisticas de Sonora y Sinaloa (1849) de José Agustín de Escudero y Noticias estadísticas del estado de Sonora de José Francisco Velasco. Noticias estadísticas de Velasco constituye el tema del presente artículo, cuyo objetivo es identificar qué aspectos del liberalismo se encuentran presentes en el libro, a fin de comprender cómo los hombres ilustrados de Sonora veían la situación de su estado a través del cristal proporcionado por el proyecto liberal; asimismo pretendemos identificar y analizar cuáles fueron los elementos que el autor utilizó para darle carácter de cientificidad a su obra.

Como antecedentes de este trabajo se encuentran dos textos, el primero es una tesis de maestría y el segundo un capítulo de libro. En el primer trabajo se analizaron memorias estadísticas elaboradas en Sonora durante la primera mitad del siglo XIX, se hizo un análisis historiográfico de varias de ellas con el objetivo de indagar el ambiente intelectual en los territorios del noroeste; asimismo se añadió la visión de los hombres de la región acerca de la problemática vivida en esta parte del país. El otro trabajo, "Sonora y el proyecto liberal a través de las reflexiones de Ignacio Zúniga”, analiza dos obras del referido autor, ${ }^{1}$ identificando en ambos documentos los princi-

${ }^{1}$ Se analizan las obras: Ignacio Zúñiga, Rápida ojeada al estado de Sonora (1835) (Hermosillo: Gobierno del Estado de Sonora, 1983), que también es analizada en la tesis de José Marcos Medina Bustos, "Sonora, tierra en 'guerra viva': visiones sobre una socie- 
pios del liberalismo que fueron retomados para aplicarlos al contexto sonorense, y de esa manera esbozar una primera explicación de cómo se fue adaptando el proyecto liberal en Sonora. ${ }^{2}$

\section{¿Quién fue José Francisco Velasco?}

José Francisco Velasco nació en Sonora en 1790. Desde los 17 años comenzó un largo camino como empleado del gobierno colonial primero y del republicano después; entre los cargos que desempeñó se encuentran los siguientes: teniente general del mineral de San Francisco y secretario de la Comandancia General de Provincias Internas. Después de la independencia fungió como presidente del primer ayuntamiento de Hermosillo en $1821 ;{ }^{3}$ también fue diputado al primer congreso general en 1822, a los congresos constituyentes del Estado de Occidente en 1824, y de Sonora en 1831; secretario general de gobierno de 1828 a 1829; trabajó en la administración de la aduana de Guaymas; se desempeñó como juez en el juzgado de primera instancia de Hermosillo en 1845; y, al año siguiente, volvió a la Secretaría de Gobierno. Su interés por el conocimiento lo llevó a convertirse en socio de la Sociedad Mexicana de Geografía y Estadística (en adelante SMGyE), y dedicar varios años a la elaboración de Noticias estadísticas del estado de Sonora. Falleció en Hermosillo el 2 de marzo de 1855 a los 65 años de edad. ${ }^{4}$

dad de frontera (1822-1850). Un análisis historiográfico de cinco memorias estadísticas de la época de autores oriundos de la región" (Tesis de maestría en Historiografía de México, Universidad Autónoma Metropolitana, 1998); y "Exposición dirigida al Sr. Benemérito de la patria general presidente D. Antonio López de Santa Anna, por el ciudadano Ignacio Zúńiga, representante suplente del mismo departamento", El siglo $X I X, 27$ de octubre de 1841.

${ }^{2}$ Zulema Trejo y Esperanza Donjuan Espinoza, "Sonora y el proyecto liberal a través de las reflexiones de Ignacio Zúniga”, en De los márgenes al centro. Sonora en la independencia y la revolución, cambios y continuidades, comp. Ignacio Almada Bay y José Marcos Medina Bustos, 155 (Hermosillo: El Colegio de Sonora, Colegio de Bachilleres del Estado de Sonora, Colección 2010, 2011).

${ }^{3}$ Información contenida en el proemio de la obra de José Francisco Velasco, Noticias estadísticas del estado de Sonora (Hermosillo: Gobierno del Estado de Sonora, 1985).

${ }^{4}$ Francisco Almada, Diccionario de historia, geografía y biografia sonorenses (Hermosillo: Gobierno de Estado de Sonora, 1983), 722. 


\section{LA OBRA}

Noticias estadisticas del estado de Sonora se publicó inicialmente por partes en el Boletín de la Sociedad Mexicana de Geografía y Estadística. La obra completa se imprimió en 1850 en la ciudad de México en la imprenta de Ignacio Cumplido con el nombre de Noticias estadisticas del Estado de Sonora. Acompañadas de ligeras reflecsiones, deducidas de algunos documentos y conocimientos practicos adquiridos en muchos años, con fin de darlas al público, y de que los sabios Estadistas puedan hacer uso de las que les parezcan oportunas, esta versión del libro se reeditó en cinco ocasiones. En 1861, fragmentos del texto se tradujeron al inglés con el título Sonora: its extent, population, natural production. Indian tribes, mines, mineral, lands, etc. etc., la traducción se publicó en San Francisco por H. H. Brancroft and Company. En 1900 y 1977, el libro se reeditó de nuevo, en ambas ediciones el crédito de la impresión siguió otorgándosele a la imprenta de Ignacio Cumplido. El título del libro se conservó tal cual hasta 1985, cuando fue publicado por el gobierno del estado de Sonora, en esa edición la obra de José Francisco Velasco aparece con el título de Noticias estadísticas de Sonora. $1850 .{ }^{5}$ En el cuadro uno se muestran los índices de la obra traducida al inglés en 1861 y la publicada en 1850; esta comparación nos indica que el libro publicado en 1985 fue una hibridación de las ediciones de 1850 y 1861, de ahí que la obra analizada en este artículo dé la impresión de ser más una colección de capítulos escritos separadamente, y compilados con un orden más o menos afortunado, que un libro concebido como tal.

Según la nota introductoria a la obra editada en $1985,{ }^{6}$ el libro que se presentaba era la reproducción de una edición de 1860 impresa por la Imprenta de Ignacio Cumplido, sin embargo, en nuestra búsqueda de ediciones anteriores a la obra no encontramos

${ }^{5}$ La información vertida en este párrafo se obtuvo de http://www.worldcat.org/title/ noticias-estadisticas-del-estado-de-sonora/oclc/760449270/editions? referer=di\&edition sView=true (Fecha de consulta: 7 de septiembre de 2015).

${ }^{6}$ Durante el periodo de gobierno de Samuel Ocaña García (1979-1985) se presentó una etapa intensa de rescate y edición de varias obras históricas, entre las obras editadas en ese momento se encuentra: José Francisco Velasco, Noticias estadisticas del estado de Sonora. 
Cuadro i. Comparación entre las ediciones de 1850, 1861

Indice de Noticias estadisticas del estado Índice de Sonora: its extend, populade Sonora... tion, natural production...

- Proemio.

- Advertencia preliminar.

- Situation, extend and boundieries

- Topografía del estado de Sonora. of Sonora.

- Situación, extensión o límites del

- Climate. estado de Sonora.

- Estado eclesiástico.

- Temperamento del estado.

- Población.

- Population.

- Capital of state.

- City of Hermosillo and its department.

- River Yaqui and its settlements.

- Presidios en lo general y lo particular. - River Mayo and its settlements.

- Minería.

- Apaches.

- 14 documentos incluidos como

- Presidio of Altar, now town of Guadalupe.

apéndices.

- Presidio of Santa Cruz.

- Presidio de Bacuachi.

- Presidio de Fronteras.

- Presidio de Tubac.

- Presidio de Tucson.

- Presidio de San Carlos de Buena Vista.

- Ceris and the island of Tiburon.

- Pueblo de ceris of San Pedro de la conquista.

- Ópatas settlements.

- Papagos.

- Mines in Sonora.

- Mines that are worked at the present day.

- Mines of iron, lead...

- Apaches tribe.

- Appendix (incluye dos documentos)

Fuente: elaboración propia a partir de los índices de las obras citadas en el cuadro.

ninguna edición de ese año, lo que sí se encontró, como se detalló anteriormente, fue una traducción parcial al inglés publicada en 1861. ${ }^{7}$ La edición de 1985 se compone de un proemio, una nota de advertencia, ocho capítulos, ${ }^{8}$ los primeros seis carecen de apartados,

${ }^{7}$ En la introducción a la edición de 1985 se indica que esta obra "ha permanecido en el olvido por casi un siglo y cuarto" (p. 9), afirmación que evidencia el desconocimiento de su autor o autora de las ediciones de 1900 y 1977.

${ }^{8}$ Topografía del estado de Sonora; Situación, extensión o límites del estado de Sono- 
el séptimo denominado "Presidios en lo general y lo particular" está compuesto por seis subapartados que contienen, cada uno, descripciones de seris y la isla del Tiburón, Pimería Alta y Baja, pueblos ópatas, papaguería; los últimos subapartados llevan por título Nota primera y Nota segunda. El capítulo octavo contiene dos subapartados, el primero se refiere a la minería y el segundo a los apaches; posteriormente viene un apéndice cuya temática es la riqueza de California -la fiebre de oro debió estar en auge cuando se escribió el apéndice-, los movimientos de la aduana del puerto de Guaymas, ${ }^{9}$ y finalmente habla acerca de las riquezas de los territorios perdidos con la guerra de Texas y la intervención norteamericana. ${ }^{10} \mathrm{El} \mathrm{libro}$ finaliza con dos trabajos que en el índice no están considerados ni como capítulos ni como apéndices: el primero de ellos se titula "Jornadas seguidas por Don José Elías para la alta California, desde la villa de Guadalupe o El Altar; el segundo es un breve relato acerca de los placeres de oro y plata que existían en Sonora. En la edición de 1850 estos dos documentos formaron parte de los catorce anexos que contenía el libro.

\section{El CONTEXTO}

Durante la primera mitad del siglo XIx, la situación en el país fue de constantes cambios en todos los ámbitos. Las diferencias entre centralistas y federalistas, liberales y conservadores en varias ocasiones culminaron en conflictos armados, además de las constantes amenazas de potencias extranjeras que en algunos casos llegaron a materializarse en invasiones al territorio nacional. Autores como Antonio Annino señalan que el país continuaba siendo una república de an-

ra; Administración pública del estado; Estado eclesiástico; Temperamento del estado; Población; Presidios en lo general y lo particular; Minería.

${ }^{9}$ Aquí cabe aclarar que Velasco fue empleado de la aduana por lo que los documentos que presenta seguramente contienen los datos que se generaron durante el tiempo de su gestión.

${ }^{10}$ La división en apartados que se realiza en la edición utilizada en este artículo responde a la estructura de la traducción parcial de la obra al inglés hecha en 1861. La versión original de 1850 no contenía estos apartados. 
tiguo régimen "con fuero militar y eclesiástico, en donde los pueblos y comunidades tenían personalidad jurídica y donde gran parte de la legislación seguía siendo la de la Nueva España". ${ }^{11}$

Por otro lado, la situación económica de la joven nación era complicada, pues, no conseguía recuperarse del impacto económico que implicó el proceso de independencia, esto aunado a una situación de baja productividad, poca inversión y escasa población en un inmenso territorio nacional, daban como resultado una situación económica cercana a la bancarrota. ${ }^{12}$ En medio de esa problemática se buscaba la forma más adecuada de dirigir los destinos del país. Los primeros esfuerzos para sentar las bases del progreso se dirigieron a la creación de leyes destinadas a regular los más diversos ámbitos de la sociedad mexicana, de este conjunto legislativo indudablemente la pieza más importante era la constitución; ${ }^{13}$ ésta como marco normativo de las nuevas naciones, México entre ellas, se consideraba, por sí y las leyes que de ella se derivaban, la panacea que permitiría solucionar los problemas que aquejaban al país; es por ello que las décadas posteriores a la independencia fueron prodigas en leyes.

En concordancia con lo que sucedía a nivel nacional, la primera constitución de Sonora se promulgó en 1831. Con anterioridad y

${ }^{11}$ Antonio Annino, "Nuevas perspectivas para una vieja pregunta", en El primer liberalismo mexicano, 1808-1855, coord. Marcela Fonseca, 52 (México: Instituto Nacional de Antropología e Historia, Miguel Ángel Porrúa, 1995).

${ }^{12}$ Luis Jaúregui, "Los orígenes de un malestar crónico. Los ingresos y los gastos públicos en México. 1821-1855”, en Penuria sin fin, historia de los impuestos en México, siglos XVII-XX, coord. Luis Aboites y Luis Jaúregui, 87-88 (México: Instituto de Investigaciones Dr. José María Luis Mora, 2005).

${ }^{13}$ Con respecto a los antecedentes de la primera constitución mexicana es necesario mirar hacia atrás, pues, es innegable la influencia que tuvo la Constitución de Cádiz en todos los documentos posteriores. La constitución gaditana de 1812 constituyó una piedra angular para la constitución de Apatzingan de 1814, para la de 1824 de corte federalista, para las centralistas de 1836 y 1843, y para las constituciones de 1857 y 1917. La constitución de Cádiz es uno de los textos jurídicos más importantes del mundo hispanoamericano; estableció por primera vez la soberanía nacional y la división de poderes como dos de sus principios fundamentales. En ella encuentran su origen muchas de las ideas democráticas y de libertades individuales orientadas a consolidar los derechos ciudadanos y limitar el poder estatal. Las constituciones eran parte fundamental de la forma en que se dirigían los destinos del estado y conforme se acercaba la mitad del siglo, esas adecuaciones se dirigían cada vez más hacia los postulados liberales de defensa de las garantías individuales y el utilitarismo. 
posteriormente a su promulgación, el congreso constituyente, y los que le siguieron, se dieron a la tarea de elaborar leyes para regular la situación de los indígenas que habitaban en la entidad; la división política del estado; el funcionamiento del congreso; la colonización; la conformación de ayuntamientos; la adjudicación de terrenos, entre otras. Este panorama de intenso trabajo legislativo no concuerda con la visión que hasta hace poco se tenía de Sonora en las primeras décadas de su existencia. Las primeras obras acerca de la historia sonorense describen una región con escasa densidad de población, serias dificultades económicas y materiales, constantemente asolada por los apaches y con una situación política compleja, cargada de conflictos y enfrentamientos entre notables, o notables e indígenas que no permitían la dedicación a tareas como la creación, promulgación y ejecución de leyes. Por otra parte, la situación que privaba en Sonora, presentada como excepcional por la historiografía sonorense tradicional, en lo general, era compartida por el resto de los estados norteños, principalmente, los que quedaron como fronterizos luego de la división territorial de 1848. La obra de Velasco se inserta en el contexto descrito anteriormente.

\section{EL PRIMER LIBERALISMO MEXICANO Y EL DESARROLLO DE LA CIENCIA}

La emancipación de las colonias americanas fue un proceso que tuvo influencia del liberalismo europeo, cuyo contenido ideológico formó parte de la base organizativa de las nuevas naciones, los regímenes políticos y la construcción civil de las jóvenes naciones de América. Este pensamiento se desarrolló de manera diferente, tuvo adaptaciones diversas en cada uno de estos países debido a que poseían necesidades y realidades diferentes. ${ }^{14} \mathrm{~A}$ pesar de estas variaciones, el liberalismo de la primera mitad del siglo XIX comparte dos características que se ponen de manifiesto en los diferentes ámbitos sociales de la centuria decimonónica, nos referimos al constitucio-

${ }^{14}$ Jorge Gaete Lagos, "Reseña de Liberalismo y poder. Latinoamérica en el siglo XIX, ed. Iván Jacksik y Eduardo Posada Carbó”, Polis 10(30) (2011): 531. 
nalismo del que ya hablamos brevemente al referirnos a la importancia de la constitución y otras leyes, y al utilitarismo. ${ }^{15}$

El utilitarismo es una doctrina filosófica cuyo principal exponente fue John Stuart Mill, ${ }^{16}$ con su ensayo El utilitarismo, publicado en 1863, en el cual afirma que el utilitarismo puede considerarse como una teoría de la felicidad, por lo cual señala que "El credo que acepta la Utilidad o Principio de la Mayor Felicidad como fundamento de la moral, sostiene que las acciones son justas en la proporción con que tienden a promover la felicidad; e injustas cuando tienen a producir lo contrario de la felicidad". ${ }^{17}$ Este planteamiento llevado al terreno de la práctica política supone obrar a favor de llevar la felicidad al mayor número de personas; esta felicidad según Mill se relaciona con dos tipos de placeres: los intelectuales o morales, y los físicos. Obviamente el utilitarismo aterrizado en el ámbito político tuvo por objetivo el placer (que aquí entenderíamos más bien como beneficio) en torno al bienestar físico de la sociedad.

A nivel nacional, la vertiente utilitarista se manifestó a partir de la década de 1830 cuando se evidenció la necesidad de desmantelar las corporaciones, buscando que sólo los ciudadanos pudieran ser propietarios, y de esta forma dar cabida a dos preceptos liberales, la creación de ciudadanos y de la propiedad individual de la tierra. Desde el punto de vista utilitarista no bastaba con legislar acerca de quién podía o no ser ciudadano, también debían implementarse las medidas necesarias para crearlos y que ejercieran los derechos que les otorgaban las leyes. Las medidas tomadas para crear a los nuevos ciudadanos fueron básicamente hacer llegar a la mayor cantidad posible de personas la educación, de forma que a través de ésta se

${ }^{15}$ Esta caracterización fue elaborada por Charles A. Hale en su obra El liberalismo mexicano en la época de Mora (1821-1853) (México: Siglo XXI, 1972), que tomó como principal referente la figura, ideas y escritos de José María Luis Mora, considerado el principal pensador liberal mexicano de la primera mitad del siglo xIx.

${ }^{16}$ Mill no fue, sin embargo, el primero en tratar el tema, en su libro El utilitarismo planta las raíces de esta doctrina filosófica en Epicuro y sus seguidores. Sin embargo, su antecesor más cercano en el desarrollo de la doctrina utilitarista fue Jeremy Bentham de quien fue discípulo.

${ }^{17}$ John Stuart Mill, El utilitarismo, traducción de Ramón Castilla (Buenos Aires: Aguilar, 1980), 6 . 
pudiera difundir el proyecto liberal y sus beneficios, entre ellos, la consecución del progreso a través de generación de riqueza mediante el cultivo intensivo de la tierra. ${ }^{18}$

La falta de educación de la población, precisamente, era una de las quejas principales de personajes interesados en la ciencia como Velasco, que conocía la problemática existente en Sonora, donde la mayor parte de la población era analfabeta, lo que dificultaba el levantamiento de información estadística y la impartición de justicia, por mencionar algunas áreas. Los señalamientos de José Francisco Velasco en torno a las consecuencias del analfabetismo están teñidos por la doctrina utilitarista en el sentido de que sin educación no es posible que los sonorenses alcancen un estado de bienestar aceptable, pues, no habrá quien pueda impartir justicia, reportar al gobierno el estatus de la entidad en todos sus ámbitos para que se tomen las decisiones que beneficien a la mayor parte de los sonorenses. Igualmente, la falta de educación obstaculizaba la formación de una ciudadanía educada en los principios liberales, lista para diseñar y ejecutar las leyes necesarias para solucionar los problemas más graves de la entidad.

En otras palabras, lo que Velasco plantea respecto a la falta de educación en Sonora conforma un círculo difícil de romper: el gobierno no cuenta con información que le permita conocer plenamente las necesidades de los sonorenses, en consecuencia, no toma las decisiones acertadas para la solución de los problemas más apremiantes o, en el peor de los casos, ni siquiera conoce esas problemáticas; y en tanto no existan ciudadanos ilustrados capaces de levantar información estadística, conocer y aplicar las leyes, la entidad avanzará lentamente por la senda del progreso.

Como integrante de la Sociedad Mexicana de Geografía y Estadística, Velasco se mantenía actualizado con respecto a los trabajos relacionados con la estadística que se generaban en otras sociedades científicas alrededor del mundo, un ejemplo se encuentra en el proemio de su obra en el cual cita como fuente al traductor de la obra Elementos de la ciencia de la estadística, escrita por uno de los so-

${ }^{18}$ Zulema Trejo y Esperanza Donjuan Espinoza, “Sonora y el proyecto liberal”, 164-165. 
cios de la Academia Real de Ciencias de Lisboa, para comparar el caso español con el mexicano, pues, en ambos era urgente la necesidad de una buena estadística que brindara al gobierno datos "preciosos e indispensables"; es importante su apreciación sobre la principal utilidad que tendría su trabajo y otros similares, al servir a los gobiernos para ejercer un mejor trabajo en materia de administración.

\section{ESTADÍSTICA Y GOBIERNO}

El desarrollo de las ciencias continuó a lo largo del siglo xix y las estadísticas tuvieron un papel preponderante, debido principalmente a la utilidad de esos datos para mejorar las decisiones de los gobernantes, puesto que contaban con mayor información para cumplir con la máxima utilitarista de llevar mayor bienestar al mayor número posible de personas. Velasco, sin duda, buscó que su obra tuviera un carácter científico, pero no dejó de lado el sentido utilitarista, ya que a lo largo del trabajo señala los errores cometidos por los gobiernos sonorenses, y propuso soluciones para las problemáticas más urgentes, entre las que se encontraba la recaudación de impuestos, la tranquilidad pública e impartición de justicia.

Una de las principales influencias científicas que permearon en las mentes destacadas del siglo XIx fue la obra publicada en París en 1811, del barón alemán Alexander Von Humboldt, ${ }^{19}$ a quien Enrique Krauze llegó a considerar "partero de la conciencia mexicana", ${ }^{20}$ pues, su ensayo apareció a los pocos meses de iniciado el proceso de independencia mexicana, provocando en su momento innumerables comentarios en la prensa internacional. Fue la respuesta a la necesidad de los criollos de un evangelio científico irreprochable sobre el país que heredaban, ${ }^{21}$ recogiendo mucho de lo que los ilus-

\footnotetext{
${ }^{19}$ Alejandro de Humboldt, Ensayo político sobre el reino de la Nueva España (México: Editorial Porrúa, 1973).

${ }^{20}$ Enrique Krauze, "Humboldt y México, un amor correspondido", Letras Libres (212) (julio 1994): 21; José Camacho Ochoa, "Humboldt y la historiografía mexicana", Vuelo Libre (1) (octubre 2006): 39; Dante Edin Cuadra, "Los enfoques de la geografía en su evolución como ciencia”, Revista Geográfica Digital (21) (enero-junio 2014): 3 .

${ }^{21}$ Krauze señala también "liberales y conservadores podían diferir sobre todos los te-
} 
trados mexicanos habían investigado en varias ramas del saber. Humboldt sintetizó esa información y la divulgó por Europa, acabando con muchas leyendas negras sobre México. A pesar de no haber sido el primer extranjero en estudiar a México, sí fue el primero que lo hizo gozando de fama y reconocimiento mundiales.

La estadística fue una ciencia que se construyó y consolidó en el siglo xix, y como en el ensayo humboldtiano, en los trabajos de tipo memoria o noticias estadísticas se incluían diversos temas, eran los principales la descripción de la geografía y la población. Como la etimología de la palabra lo muestra, las estadísticas están conectadas con la construcción del estado, con su unificación y administración. Involucran el establecimiento de formas generales, de categorías de equivalencias y terminologías que trascienden las singularidades de las situaciones individuales; también las categorías de ley (el punto de vista judicial) o normas y estándares. ${ }^{22}$

Las estadísticas económicas y poblacionales fueron las que más interesaron al estado liberal mexicano en su proceso de consolidación, por estar directamente ligadas con la administración pública. A diferencia de los tiempos coloniales, la estadística poco a poco dejó de ser un secreto de estado y se volvió parte del conocimiento público, una pedagogía nacional. Se constituyó en una indagación científica con la que se esperaba redescubrir al país y acuñar las objetivas medidas de la patria. La nueva disciplina nació con la misión de ofrecer medidas e imágenes de su población, los medios para contenerla y controlarla en su camino al progreso. ${ }^{23}$

En México, al no existir hasta antes de 1882 una institución oficial encargada de la generación y el manejo de la información estadística, los miembros de la SMGye fueron quienes contribuyeron a

mas imaginables -y matarse por ellos- salvo en la admiración por el Barón de Humboldt". Enrique Krauze, "Humboldt y México", 22.

${ }^{22}$ Alain Desrosières, La política de los grandes números. Historia de la razón estadística, traducción del francés de Mónica Silvia Nasi (Santa Cruz de Tenerife: Editorial Melusina, 2004), 8.

${ }^{23}$ Laura Cházaro, "Imágenes de la población mexicana: descripciones, frecuencias y cálculos estadísticos", Relaciones Estudios de Historia y sociedad xxir(88) (otoño 2001): 18 . 
formar la que sería la Estadística Económica Nacional, ${ }^{24}$ definida por Sergio de la Peña como:

Información cuantitativa que fue publicada en su momento o posteriormente sobre: características de la población, producción y circulación de bienes y servicios, finanzas públicas y privadas, banca, comercio exterior e interior, precios, trabajo y ocupación, entre otros. Es pues, la información cuantitativa sobre cuestiones significativas acerca de los muy variados aspectos de la actividad económica, en lo referente a la nación y su conjunto. ${ }^{25}$

Para el caso de las estadísticas de los estados, aquellas elaboradas en cumplimiento de leyes locales, fueron los mismos funcionarios quienes las elaboraban, contando, en algunos casos, con asesoría de miembros de la SMGye. De la Peña destaca la relación entre la estadística nacional y el Estado, que es importante, pues, a lo largo de todo el siglo XIX, esa vinculación tuvo un sentido funcional y utilitario. El Estado era el principal usuario de esas estadísticas, con exclusividad para su uso, ${ }^{26} \mathrm{y}$ casi el único con la capacidad financiera, organizativa y técnica ${ }^{27}$ para captar, concentrar, depurar y publicar la información estadística. ${ }^{28}$ Poco a poco se fue consolidando la relación entre los que contaban a la población y el Estado, hasta que éste crea una institución a su cargo, con el objetivo primero de conocer el número y características de la población mexicana.

${ }^{24}$ La SMGye no era parte del aparato estatal, y gran parte de los recursos para su funcionamiento provenían de las cuotas de sus miembros (como continúa funcionando hasta hoy).

${ }^{25}$ Sergio de la Peña y James Wilkie, La estadistica económica en México. Los orígenes (México: Siglo XXI Editores, UAM-Azcapotzalco, 1994), 08.

${ }^{26}$ A lo largo del siglo XIX, se fue dando cada vez mayor apertura de parte de los Estados nacionales para publicar y compartir las cifras que obtenían en sus conteos estadísticos, principalmente, en la segunda mitad.

${ }^{27}$ Excepto por la Iglesia.

${ }^{28}$ En el caso de la obra de Velasco, ésta no fue financiada por el gobierno del estado de Sonora, pero si se presentaron entre 1848 y 1878 varios intentos por parte de las administraciones estatales para lograr elaborar sus propios trabajos estadísticos, aunque los resultados no fueran siempre los esperados. La construcción de una estadística nacional no llegó a consolidarse sino hasta fines del siglo XIX. 


\section{Noticias ESTAdísticAs DEL ESTADO DE SONORA, ENTRE LO CIENTÍFICO Y LO UTILITARISTA}

En "Sonora, tierra en 'guerra viva': visiones sobre una sociedad de frontera (1822-1850)" se propone una clasificación para las obras del tipo memorias o noticias estadísticas, las cuales son catalogadas en obras político-administrativas: "son aquellas que considero comparten la característica de privar en ellas una orientación politico-administrativa, en tanto que sus descripciones del territorio, los habitantes y las instituciones públicas van encaminadas a sostener propuestas de corte político-administrativo". ${ }^{29}$ Otra clasificación es la denominada aspiración científico-estadística; al respecto se señala:

Estas obras se caracterizan por que la descripción que hacen del territorio y sus habitantes no es el soporte de propuestas político-administrativas, aunque también las hacen; ya que su principal objetivo está definido por dar a conocer al gobierno general lo que son estos territorios, para formar la estadística nacional y hacer algo en "pos de la civilización". ${ }^{30}$

Medina ubicó la obra de Velasco entre las segundas, considera que tiene más peso la búsqueda de cientificidad que sus pretensiones utilitaristas. Sin embargo, consideramos que la obra puede catalogarse como político-administrativa y científica, ya que el trabajo reúne ambas características como puede verse en el siguiente ejemplo:

Los representantes de Sonora al Congreso general, en los años de 1835 y 1836, hicieron una exposición al supremo gobierno, dibujando enérgicamente el triste cuadro que en época $[s i c]$ guardaban las compañías presidiales, por el abandono que padecían; la despoblación que sufrían las fronteras por las continuas depredaciones de los apaches proponiendo las únicas medidas que podían poner término a tan acerbos y terribles males; y como en dicha representación se comprenden no sólo los fundamentos

${ }^{29}$ Medina Bustos, "Sonora, tierra en 'guerra viva', 60.

${ }^{30}$ Ibid., 68. 
en que apoyaron sus asertos, sino muchos puntos concernientes a la posición topográfica de la frontera, así como de los bienes de que es susceptible bajo los auspicios de una administración justa y paternal, y como por lo expuesto, y los conocimientos que ministra al tratar de una de las partes más interesantes de Sonora, sea compatible con el fin y esencia de estas apuntaciones estadísticas, nos ha parecido conveniente insertar a la letra dicho documento. ${ }^{31}$

Como puede apreciarse en este fragmento, las características científicas de la obra están presentes al hablar Velasco de los motivos por los cuales insertará el documento enviado al gobierno, que si bien el autor de Noticias estadísticas del estado de Sonora advierte que contiene medidas utilitaristas, también le sirve para darle "esencia" a sus notas estadísticas. En términos contemporáneos podríamos decir que dar esencia significa darle sustento a lo que se está escribiendo, y ese sustento tiene que ver, evidentemente, con uno de tipo científico. La obra de Francisco Velasco no puede clasificarse en una sola de las categorías planteadas por Medina Bustos, en todo caso cabría en dos de ellas. Consideramos que catalogar la obra de Velasco en una u otra categoría no es parte substancial de este artículo, el motivo del ejercicio anterior básicamente es dar una idea del tipo de noticias estadísticas que se escribieron en los hoy territorios sonorenses, así como mostrar que no todas admiten ser clasificadas en una sola categoría.

Francisco Velasco ${ }^{32}$ no proporciona una definición de estadística retomada de alguna fuente, ni elabora una propia, más bien mencio-

${ }^{31}$ Velasco, Noticias estadísticas, 81-82.

${ }^{32}$ Medina considera que los autores de estas memorias regionales, si bien tenían una aspiración estadística y por lo tanto científica, no se relacionaban directamente con la manera en que otros como Humboldt buscaban elaborar trabajos científicos, en el sentido de buscar leyes generales de la naturaleza y la sociedad, sino más bien en el nivel del funcionario ilustrado que busca proporcionar información al gobierno, utilizando los modelos estadísticos que habían establecido el tipo de datos que eran considerados necesarios para una buena administración pública. Así será un elemento central de estas dos obras el destinar un espacio considerable para definir lo que conciben por estadística, a los problemas que tienen para elaborarla y cómo consideran se podrían resolver (Medina Bustos, "Sonora, tierra en 'guerra viva', 66). 
na los elementos que deben incluirse en un trabajo para que pueda considerarse como estadística, y además útil para la administración pública. En el proemio señala:

Todos los gobiernos cultos, todos los sabios y aun los hombres que solo poseen una mediana instrucción, están de acuerdo que sin una estadística que dé a conocer la situación actual del Estado, sus fuerzas y recursos presentes, morales y materiales, como resultados de su gobierno; su resultado, número, civilización e industria de la población, y elementos de progreso de que es susceptible, no puede haber gobierno en todos los ramos de la administración, y especialmente en el sistema tributario. ${ }^{33}$

Velasco destaca que son muy variados los aspectos que deben incluirse en un trabajo para que éste merezca llamarse memoria o noticia estadística, además establece una relación entre el tipo de información que debe generarse y el uso que debería hacerse de ella. Especialmente señala la necesidad de que los datos estadísticos sirvan para mejorar la recaudación, ya que en esa época el cobro de impuestos era un problema acuciante. ${ }^{34}$ Asimismo, en la advertencia preliminar, el autor de Noticias estadísticas explica las dificultades de elaborar la estadística, sobre todo, en lo relacionado al conteo de población, por lo que menciona que ese apartado se compone de "algunas noticias" que pudieran dar luz sobre el número aproximado de habitantes del estado.

${ }^{33}$ Velasco, Noticias estadísticas, 16.

${ }^{34}$ La problemática por la baja recaudación fiscal en los municipios de Sonora fue una constante durante todo el siglo XIX. Al respecto pueden verse los trabajos de Esperanza Donjuan Espinoza, "Las finanzas públicas en Sonora en la primera mitad del siglo XIX. La cuestión fiscal", en Memoria del Segundo Congreso de Historia Económica de México 2004. http://www.economia.unam.mx/amhe/memoria (Fecha de consulta: 11 de septiembre de 2014); "Las penurias de la hacienda pública y las incursiones apaches en Sonora, 1830-1848", ponencia presentada en el XVII Simposio de la Sociedad Sonorense de Historia, 22 al 27 de noviembre, Hermosillo, 2004b; y Zulema Trejo, "La época de Pesqueira: facciones, riqueza y poder. Sonora 1850-1876" (Tesis de maestría en Historia, El Colegio de Michoacán, 20 de septiembre de 2001). 


\section{LOS TEMAS ESTADÍSTICOS EN LA OBRA de Francisco Velasco}

Los principales temas abordados por Velasco en su trabajo son: topografía; situación, extensión y límites; administración pública; estado eclesiástico; temperamento del estado; población, presidios, minería y apaches. Estos temas se desarrollan desde una forma muy particular de estadística, lejos de la utilización de herramientas metodológicas que facilitan el manejo de información numérica, como las tablas, cuadros y gráficas y el uso del cálculo para estimar datos como el número de población. El desarrollo de la estadística como ciencia fue un proceso largo que tenía siglos desarrollándose en Europa. ${ }^{35}$ En México, durante el siglo XIX se consolidaron muchas de las aportaciones de dicha ciencia, no sin que antes se desarrollaran discusiones y se aplicaran diferentes formas de concebirla desde las tres tradiciones estadísticas europeas.

En 1833, casi simultáneamente a la fundación de la SMGye, Manuel Ortíz de la Torre elaboró un trabajo con la intención de homo-

${ }^{35}$ Desde el siglo xvir en Europa se desarrollaron diversas tradiciones o escuelas que buscaban la forma más adecuada para el levantamiento y manejo de la información estadística de las naciones. Las principales fueron: escuela alemana, inglesa y francesa. Alemana: A fines del siglo Xvir y principios del XviII en Alemania se desarrollaron postulados que pugnaban por una descripción cualitativa, que buscó incluir en la descripción de los hechos sociales a la cuasi totalidad de la experiencia humana. Centrándose más en la descripción del Estado que de la población, acercándose más a una descripción histórica y jurídica que a una naciente demografía. A pesar de que para mediados del siglo xix ya había sido rebasada en Europa (al grado de desaparecer como referente hacia 1880), en México aun continuaba siendo una importante influencia. Inglesa: Los censos como tales, sobre todo, relacionados con la administración pública de las naciones, comenzaron a retomarse en occidente hasta el siglo XVII en Inglaterra, insertándose dentro de la llamada aritmética política inglesa, que utilizó el cálculo estadístico y métodos indirectos principalmente. Para elaborar sus estimaciones, los estadistas británicos se basaron en las cifras de nacimientos y defunciones. La escuela inglesa proporcionó importantes contribuciones para el desarrollo posterior de la demografía y la estadística. Francesa: su contribución al desarrollo de la disciplina radicó, ante todo, en la puesta en funcionamiento de una metodología rigurosa de relevamiento estadístico consistente en el desarrollo de grandes encuestas y censos. El perfeccionamiento de este modelo, tendiente a una rigurosidad metodológica se llevó a cabo desde los siglos XV y xvı y se basaba en el individuo como unidad de análisis. Hernán Otero, Estadística y nación. Una historia conceptual del pensamiento censal de la Argentina moderna, 1869-1914 (Buenos Aires: Prometeo Libros, 2006), 70-75. 
geneizar la información estadística que era enviada a la Contaduría de Propios y arbitrios, a raíz de que en 1831 esta oficina fuera designada como la responsable de elaborar las estadísticas nacionales. Desde el título se puede apreciar el carácter descriptivo de la obra: Instrucción sobre los datos o noticias que se necesitan para la formación de la estadistica de la república conforme a la obligación 8 a del art. 161 de la constitución y a la atribución $2^{a}$ del art. 2 do de la ley del 30 de septiembre de 1831, añadiéndose los respectivos a otros ramos que se consideran importantes para el mejor logro del mismo fin. La Instrucción da cuenta de los datos que se necesitan para la formación de la estadística de la república y del método por emplearse, utilizando la descripción exhaustiva de lo observado. La propuesta del autor se refiere a tres aspectos: 1) información sobre el estado físico de la República y producción de los reinos mineral, vegetal y animal; 2) estado civil y sociedad (dentro de este apartado fue incluido el apartado sobre población); y 3) estado político (federación y gobiernos estatales).

Manuel Ortiz de la Torre ${ }^{36}$ fue uno de los socios fundadores del Instituto Nacional de Geografía y Estadística y fue el principal impulsor en México de la estadística alemana. ${ }^{37}$ Según él, las estadísticas debían representar cada porción del país; cada cosa vista debía ser meticulosamente descrita, entre más detalles se sumaran, más objetiva sería, pues, ello suponía eliminar toda suposición y confiar en lo visible y lo observable (Cházaro 2001, 22). Ortiz entendía por estadística "todas las noticias respectivas a objetos que dicen relación

${ }^{36}$ Originario de Álamos, Sonora, se desempeñó como Ministro de Relaciones Interiores y Exteriores (1829-1830), contador general de Propios y Arbitrios del D. F. y diputado federal. INEGI, Catálogo de documentos históricos de las estadísticas en México (siglos XVI-XIX) (México: Instituto Nacional de Estadística, Geografía e Informática, 2005).

${ }^{37}$ A pesar de la publicación del trabajo de Ortiz en 1833, desde años anteriores, la escuela prusiana contaba con críticos, como Juan José Martínez de Lejarza, importante botánico, además de regidor y diputado por su natal Michoacán, quien opinó que se debía abandonar un modelo que exigía tantas descripciones y quedaba en mero recuento literario, señalando además "la verdadera población se calcula: los datos geográficos, el rumbo y las distancias se averiguan; y el estado actual de la Provincia se presenta como es”. Cita de Juan José Martínez de Lejarza, Análisis estadístico de la Provincia de Michoacán en 1822, 11 y 15, en Laura Cházaro, "Imágenes de la población mexicana", 27. El trabajo de Lejarza en esta obra fue reconocido por Lucas Alamán, quien lo propuso como modelo para elaborar las estadísticas estatales. 
inmediata a la prosperidad general de la nación o bienestar de sus habitantes". ${ }^{38}$ Si bien, el trabajo de Ortiz iba dirigido a funcionarios y gobernadores, Velasco siguió la mayor parte de sus instrucciones al elaborar su obra.

Para redactar sus Noticias estadisticas, Velasco se apoyó en "personas de algunos conocimientos científicos que he consultado", "mapas que he tenido a la vista" y "náuticos", ${ }^{39}$ pero no menciona en concreto sus fuentes. Muchas de las apreciaciones que presenta están basadas en su propio conocimiento y observaciones: "en la frontera hay poblaciones en que el invierno se alarga más que el verano, como Arizpe, Bacoachi y Fronteras quizá por su mayor proximidad al polo" ${ }^{40}$ Como funcionario de las Provincias Internas de Occidente, Velasco posiblemente conoció por propia experiencia la estación invernal en estos lugares, cuya duración atribuyó a la mayor cercanía de estas poblaciones con el polo norte, posibilidad que matiza con un "quizá" para evitar, tal vez, que su suposición fuese catalogada de errónea por los integrantes de la SMGyE. Cabe también la posibilidad de que su observación respondiera al clima intelectual de la época, que otorgaba a factores geográficos y climáticos una influencia importante en el carácter de los hombres. ${ }^{41}$

${ }^{38}$ Manuel Ortiz de la Torre, Instrucción, 1833, 1, en Laura Cházaro, "Imágenes de la población mexicana”, 22.

${ }^{39}$ Velasco, Noticias estadísticas, 25-26. A pesar de las reformas efectuadas en la marina española durante la primera mitad y los decenios centrales del setecientos, no pudo cubrirse el retraso relativo respecto a la gran competidora, la marina británica. La conciencia de dicho retraso y la necesidad de asegurar el control del creciente comercio ultramarino dio lugar a la creación de nuevos centros de estudios náuticos, en los cuales se fueron implantando nuevos programas docentes. En particular, las reformas emprendidas a partir de 1780 supusieron la necesidad de modernizar los libros de texto y provocaron la publicación de manuales actualizados, algunos de los cuales seguirían utilizándose durante todo el siglo XIX. Los programas entonces adoptados tuvieron un efecto inesperado sobre la situación de la geografía, cada vez más identificada con la geografía astronómica y cuya presencia fue debilitándose en favor de otras materias más necesarias a las nuevas técnicas de navegación, tales como las matemáticas y la astronomía náutica. Horacio Capel, Geografía y matemáticas en la España del siglo XVIII, capítulo VIII (Barcelona: OKIOS-TAU, 1982), 195.

${ }^{40}$ Velasco, Noticias estadísticas, 45.

${ }^{41}$ La cuestión del determinismo alcanzó su punto culminante con los planteamientos del geógrafo alemán Federico Ratzel a fines del siglo xIX, véase Ennid Gladys Miguel, "Enfoques, tendencias y escuelas geográficas. De la geografía clásica o tradicional a los estudios culturales", Párrafos Geográficos (2) (2003): 1. 
El apartado del capítulo siete referente a los apaches constituye también una muestra fehaciente de que mucho de lo escrito por Velasco lo conoció de primera mano. Su permanencia como empleado de la comandancia militar de las Provincias Internas de Occidente, debió proporcionarle acceso a todo tipo de detalles en relación con el combate de los apaches, que posteriormente le sirvieron para redactar lo referente a ellos. Que la mayor parte de información haya sido de primera mano y la forma en que Velasco describe sus observaciones, lo acercan a lo propuesto en la Instrucción de Ortíz de la Torre, quien definió a la estadística como un orden clasificatorio que va de lo general al detalle de la descripción geográfica de cada clima; de los tipos de atmósfera a las temperaturas locales; para pasar posteriormente al número e historia de la población; $\mathrm{y}$, finalmente, la riqueza vegetal y animal. Según Ortiz, sólo lo descrito detalladamente, lo clasificado y ordenado, era considerado real. ${ }^{42}$

Con respecto a las personas que pudieron haber fungido como informantes de Francisco Velasco las opciones que se pueden plantear son pocas. Por su calidad de empleado en el gobierno colonial y republicano, es probable que tuviera contacto con Ignacio Zúńiga, el autor de Rápida ojeada al estado de Sonora; por los anexos de su libro es lógico suponer que había algún tipo de relación entre Velasco, José Elías y Dionisio González (los protagonistas del viaje a California que incluye en su libro), asimismo, como integrante de los congresos constituyentes del Estado Interno de Occidente y del de Sonora debió tener contactos con los hombres considerados los ilustrados de la entidad en ciernes.

En términos generales, Noticias estadísticas contiene información relativamente breve en cuanto a las descripciones topográficas, la administración pública y los apuntes de población; se extiende más en cuestiones descriptivas relacionadas con los presidios y los grupos indígenas, sin que ello implique que se pierda el carácter estadístico del texto, puesto que en el periodo de publicación de estas noticias estadísticas, las obras podían o no contener cuadros e información numérica, o bien centrarse más en aspectos descriptivos, dependien-

${ }^{42}$ Laura Cházaro, "Imágenes de la población mexicana”, 23. 
do del tema que se tratase, así como de las preferencias e intereses del autor. A continuación retomaremos algunos de los apartados que consideramos más relevantes.

\section{Administración pública del estado}

Los aspectos relacionados con el utilitarismo se encuentran a lo largo de toda la obra de José Francisco Velasco, sin embargo, es en el apartado relacionado con la administración pública donde se esbozan con mayor claridad, ya que ahí habla tanto de las problemáticas que existían en el gobierno sonorense, como de las soluciones que nuestro autor propuso para las mismas. La forma como se organizó este apartado siguió el orden de los tres poderes de gobierno: Legislativo, Ejecutivo y Judicial. Con respecto al primero se refiere a la Constitución del Estado de 1848, así como a las disposiciones referentes a los diputados y la representación de los mismos.

Acerca del poder Legislativo informó que estaba compuesto por once diputados e igual número de suplentes, que esta cantidad podía aumentarse si el número de población se incrementaba. Esta disposición se mantuvo vigente por lo menos hasta 1861. La conformación del congreso estatal con base en el número de población favorecía obviamente a los distritos más poblados Hermosillo, Guaymas, Ures y Álamos que eran además las sedes del poder económico y político de la entidad. Este trabajo no tiene como objetivo analizar la participación de los diputados en el congreso estatal, de forma que sólo seńalaremos que durante los debates del congreso que promulgó la constitución de 1861 fueron justamente los diputados de los distritos mencionados líneas arriba, los que propusieron reformas y lideraron los debates. ${ }^{43}$

José Francisco Velasco señaló, también, la forma como se elegía a los integrantes del poder Legislativo y su independencia con respecto al poder Ejecutivo, sin embargo, sobre este último punto indicó que en la práctica no existía esa independencia. En este sentido,

${ }^{43}$ Para mayor información véase Zulema Trejo, "Constituyentes y constitución. Sonora 1857-1861”, Historia Mexicana 59(3) (enero-marzo 2010). 
consideramos necesario aclarar que la afirmación de Velasco debe matizarse con los hechos que la rodeaban. Desde fines de la década de 1830 y prácticamente toda la de 1840, Sonora, al igual que el resto del país, vivió el enfrentamiento entre centralistas y federalistas, con los consiguientes cambios en el sistema administrativo, que sustituyó a los congresos estatales por juntas o asambleas departamentales. Con la reinstalación del sistema federalista se restablecieron los congresos locales, sin embargo, en el caso de Sonora, el congreso de 1847 no respondió a un proceso electoral, sino a una designación por parte del grupo de notables que emergió triunfante de la lucha Gándara-Urrea cobijada bajo el manto del enfrentamiento nacional entre federalistas y centralistas.

La afirmación de Velasco en el sentido de que el congreso de Sonora no tenía independencia del gobernador tiene sentido dentro del contexto enunciado en el párrafo anterior, que no en la etapa previa y posterior a los acontecimientos narrados arriba, ya que, en la década de 1850, el congreso estatal estuvo más tiempo disuelto que en funciones, debido a la conflictividad interna, o suprimido en razón de los cambios de sistema de gobierno a nivel nacional. Cuando, finalmente, el país adquiere un cierto grado de estabilidad hacia la década de 1870, el congreso sonorense no se mostró dócil a los designios del gobernador en turno, por el contrario, constituyó un elemento de regular oposición al poder ejecutivo hasta 1875-1876 aproximadamente. ${ }^{44}$

En relación con la forma como se elegía a los diputados, Velasco consideró que las elecciones deberían haber sido más directas, con representantes más aptos y virtuosos que no buscaran sólo sus intereses. De nuevo con estas afirmaciones, Velasco critica, de forma no muy velada, al congreso que estaba en funciones cuando concluyó la redacción de sus Noticias estadisticas, conformado en su totalidad por integrantes o aliados de la red Gándara-Ińigo-Cubillas-Aguilar, que salió victoriosa de su conflicto con José Urrea y sus aliados. ${ }^{45} \mathrm{De}$

${ }^{44}$ Para mayores detalles respecto a la relación entre poder Ejecutivo y Legislativo en Sonora, véase el capítulo 2 de Zulema Trejo, Redes, facciones y liberalismo. Sonora, 18501876 (Hermosillo: El Colegio de Sonora, 2012), 83.

${ }^{45}$ En la historiografía sonorense se conoce como conflicto Gándara-Urrea a la lucha 
hecho, en la página treinta del libro, nuestro autor señala que Sonora carecía de una población con la capacidad de exigir que el gobierno del estado dejara de estar en manos de "determinadas familias". ${ }^{46}$

En relación con el poder Ejecutivo, criticó las excesivas facultades que la constitución le otorgaba al gobernador. Ciertamente, la carta constitucional sonorense facultaba al gobernador para intervenir en todos los ámbitos del gobierno sonorense, sin embargo, esa situación no era exclusiva del gobernante sonorense porque, salvo en contados casos, las facultades del gobernador repetían las que a nivel nacional tenía el presidente de la república, ${ }^{47}$ Francisco Velasco, quien había fungido como diputado nacional y local, quien ejerció el cargo de secretario de gobierno del estado debía conocer bien las constituciones nacional y estatal, sin embargo, su crítica relativa a las facultades del gobernador pueden leerse como una muestra de oposición a los gobernadores emanados de la red Gándara-IńigoCubillas-Aguilar.

La sugerencia en torno a que el gobernador debería contar con un consejero que fuese profesor en derecho deja ver dos cuestiones, la primera y más obvia es que Velasco desconfiaba de la preparación de los notables sonorenses que ocuparon la gubernatura. Dado que se desempeñó en dos ocasiones como secretario de gobierno, debía tener experiencia de primera mano con respecto al desempeńo de los gobernantes sonorenses, que como él dijo en otra parte de sus Noticias estadísticas tenían muchas facultades, algunas de las cuales los capacitaban para actuar en el ámbito judicial; en segundo lugar, la sugerencia de un consejero experto en derecho como apoyo al titular del Ejecutivo, puede considerarse un indicio de que nuestro autor consideraba que, de una u otra forma, el gobierno debía estar apoyado en hombres ilustrados, cuya educación les permitiera tomar las mejores decisiones, y aquí embonamos con una cuestión liberal,

por el control del poder estatal que mantuvieron los grupos de notables encabezados por Manuel María Gándara y José Urrea respectivamente. Este conflicto de índole local se imbricó, debido a la filiación federalista de Urrea, con la lucha que a nivel nacional mantenían federalistas y centralistas.

${ }^{46}$ Velasco, Noticias estadísticas, 30.

${ }^{47}$ Zulema Trejo, Redes, facciones, 83. 
aquella que veía en la educación el medio para crear ciudadanos que hicieran progresar a su país.

La consideración de Velasco en torno a la necesidad de contar con hombres ilustrados en el gobierno se corrobora con su crítica a las juntas particulares que, de acuerdo con la constitución, el gobernador podía nombrar si lo deseaba para consultarles asuntos concretos. Francisco Velasco consideró que las juntas particulares eran inútiles por su carácter de eventuales, y porque no asumían ninguna responsabilidad respecto a las sugerencias que daban, es decir, no corroboraban si el gobernador las seguía o no. Aunado a lo anterior señaló la falta de ciudadanos "de conocimientos e instrucción", por lo que se dificultaba también nombrar candidatos a puestos de elección popular con las aptitudes necesarias para desempeñar dichos cargos. Seńaló que los "unionistas" apelaban a esto en la Revolución de 1830, al considerar que en Sonora no había suficientes personas letradas que fueran capaces de dirigir los destinos del estado. ${ }^{48}$

Velasco consideró que los prefectos, al igual que el gobernador, gozaban de facultades extraordinarias sin que esto sirviera para remediar muchas situaciones como la falta de progreso y policía (seguridad). El autor llamó la atención sobre la carencia de leyes de policía (rural y urbana). Se lamentó, por el contrario, de la existencia de un reglamento de policía urbana, que imponía castigo de 12 a 200 azotes, pena degradante en el siglo de las luces a su juicio, ${ }^{49}$ lo que atribuyó al poco saber en política y sistema parlamentario de los representantes del pueblo.

Sobre el poder judicial, señaló que tristemente no había jueces de primera instancia profesores en derecho, al contrario, algunos apenas si sabían leer o escribir, y algo similar ocurría con los ministros del supremo tribunal. ${ }^{50}$ Debido precisamente a esta situación, en el caso de las disposiciones del gobierno del estado que ordenaron la elaboración de las estadísticas de población, no había buenos resultados, pues, en

${ }^{48}$ Francisco Velasco estaba haciendo alusión al conflicto que hubo entre los notables que pedían la separación de Sonora y Sinaloa, y los que abogaban para que permanecieran unidas como Estado Interno de Occidente. Velasco, Noticias estadisticas, 32.

${ }^{49}$ Velasco, Noticias estadísticas, 33.

${ }^{50}$ Ibid., 34. 
muchos de los casos, las personas encargadas de levantar la información carecían de los conocimientos más elementales.

A pesar de estar consciente de que la problemática relacionada con la mala administración de justicia, y con la ausencia de personas aptas para levantar censos de población, se debía a la poca educación de los habitantes del estado, Velasco no dedica ningún apartado de su obra a explicar la situación de las escuelas que existían, pues, si bien era cierto que sólo había instrucción de primeras letras, no menciona cómo ni dónde se daba este tipo de instrucción. Respecto a los que deseaban una educación superior, menciona que sus familias debían enviarlos fuera del estado, algo que muy pocas personas se podían permitir.

\section{CÁlCulos y APROXIMACIONES}

Para la construcción del apartado de "estado eclesiástico", Velasco retomó la información que Juan Miguel Riesgo y Antonio José Valdés presentaron en su Memoria de $1828,{ }^{51}$ posteriormente consideró que al igual que entonces, para los años en que redactó sus Noticias estadísticas se continuaba con la escasez de ministros en la diócesis de Sonora; ${ }^{52}$ también lamentó la serie de robos cometidos en las iglesias, por lo que juzga que "parece haber desaparecido la religión de nuestros mayores y aquella moral consiguiente, que es tan necesaria para la felicidad de los pueblos". ${ }^{53}$ En este punto, Velasco establece una relación directa entre la religión, la moral y la felicidad, lo cual puede parecer contradictorio a los intereses liberales de la época, pero no lo era. Los gobernantes sonorenses mantuvieron relaciones cordiales con la Iglesia durante todo el siglo XIX, que además no era ésta tan rica e influyente como en otros estados del país. ${ }^{54}$

${ }^{51}$ Juan Miguel Riesgo y Antonio José Valdés, Memoria estadística del Estado de Occidente (Guadalajara: Imprenta á cargo del C.E. Alatorre, 1828).

52 Ibid., 40.

${ }^{53}$ Ibid., 46.

${ }^{54}$ Para entender la relación de la sociedad sonorense con la Iglesia católica y la influencia de la misma, véase la obra de Dora Elvia Enriquez Licón, Pocas flores, muchas espinas. Iglesia católica y sociedad en Sonora (1779-1912) (México: Pearson, Universidad de Sonora, 2012). 


\section{Grupos indígenAS}

En cuanto a los grupos indígenas del estado, escribió apartados sobre los ópatas, pápagos, seris y apaches,${ }^{55}$ aunque en el referente a población describe detalladamente las costumbres de los yaquis y mayos, además de las características físicas de los mismos y de los valles que habitan. Abiertamente no sugirió medidas para colonizar el valle del yaqui, pero si menciona que sólo se cultivaban garbanzo, maíz, lenteja y un poco de trigo y frijol que los indios iban a comerciar al puerto de Guaymas, aun cuando con base en algunos pocos experimentos se supo que el fértil valle produciría en abundancia caña y algodón en caso de ser explotado por los blancos. ${ }^{56}$ Respecto a los yaquis, Velasco señaló que a pesar de ser inclinados al vicio y desconfiados por naturaleza, eran los únicos brazos de Sonora para el trabajo de las minas, labores de campo, construcción de edificios y demás ocupaciones de una sociedad, además de ser buenos para las artes (flauta, violín, arpa o guitarra), y muy rápidos para aprender oficios como la herrería o carpintería, por lo que consideró que de haber sido educados debidamente para ser justos y benéficos desde tiempos del gobierno español, en vez de los males que causaron, serían útiles y benéficos. ${ }^{57}$

La sociedad de la época, en general, y la sonorense, en particular, consideraban a los grupos indígenas como un lastre para el progreso, aunque en el caso de los yaquis su fama de buenos trabajadores propiciaba que se tuviera de ellos una percepción ambigua, ya que por un lado significaban siempre un problema, pues, se habían mantenido separados del gobierno, con sus propias autoridades y protagonizando intermitentemente rebeliones de diversa magnitud; mientras que, por otro, se les consideraba los mejores trabajadores de la entidad. El valle del yaqui, que habitaban, era codiciado por su

${ }^{55}$ Los apaches habitaban la región norte del estado, sin embargo, con la nueva división territorial de 1848, y la posterior venta de la mesilla (1853), dejaron de serlo, pero continuaban con sus incursiones robando ganado y productos, además de asaltar viajeros o asolar pueblos y ranchos. La amenaza para la seguridad que representaban era tal que hubo muchos esfuerzos de parte del gobierno sonorense por controlarlos o eliminarlos. No hay información sobre los miembros de los grupos más numerosos: yaquis y mayos.

${ }^{56}$ Velasco, Noticias estadísticas, 70-71.

${ }^{57}$ Ibid., 75. 
potencial agrícola. El mismo Velasco señala que desde 1825 hasta mediados del siglo hubo conflictos a causa de los levantamientos yaquis, liderados por Juan Banderas, iniciados a causa de la pretensión de las autoridades de querer cobrarles impuestos por sus solares. La ferocidad de los indios al sentirse amenazados era bien conocida y temida por las autoridades; las opiniones de Velasco al respecto son ambivalentes, pues, señala los defectos de los yaquis, pero también destaca sus virtudes.

En el caso de los mayos no hace una descripción del valle ni de los productos que se cultivan; sobre la población señala que eran de la misma raza que los yaquis, con el mismo idioma y costumbres. ${ }^{58}$ Sobre los ópatas, Velasco consideró que fueron los que manifestaron un carácter franco, dócil y con simpatía hacia "los blancos", por lo tanto fueron inclinados al orden y a la paz. Asimismo, reconoció el valor de los ópatas, que formaban parte de las compañías presidiales de Bacuachi, Tubac y Bavispe en las campańas contra los apaches. Francisco Velasco anotó que los ópatas se dedicaban al laborío de tierras, que no estaban tan corrompidos por la "beodez" como los yaquis, seris y pimas. Consideró que al ser la tribu de "más moralidad" en el estado, eran quienes mejor relación tenían con la sociedad blanca-mestiza "hasta el grado de que se vaya confundiendo su raza con la nuestra". 59

De acuerdo al autor de Noticias estadísticas, los ópatas encajaban perfectamente en el tipo de personas que tenían las cualidades para ser considerados ciudadanos, a comparación de los otros grupos indígenas, por ejemplo, los seris que eran nómadas y habían permanecido al margen de la evangelización jesuita.

Velasco al igual que sus contemporáneos compartía la opinión de que mientras los indígenas estuvieran más cercanos a las costumbres de la sociedad blanca-mestiza eran más apacibles y apreciados; pero cuanto más diferentes fueran de ésta, se les consideraba más salvajes. A partir de lo que Francisco Velasco escribió respecto a los grupos indígenas se puede inferir que los consideraba como mano

${ }^{58}$ Lo cual es erróneo, en su lengua hay pequeñas variaciones, y en cuanto a sus festividades y tradiciones también hay diferencias.

${ }^{59}$ Velasco, Noticias estadisticas, 138. 
de obra, con pocas facultades e inteligencia, propensos a la bebida, hoscos y desconfiados. La integración o mezcla de los pueblos indios con los blancos era al parecer lo más deseable para el autor de Noticias estadisticas del estado de Sonora.

\section{OTROS ASPECTOS QUE CONSIDERAR}

Dentro del mismo apartado sobre población, Velasco describe las principales poblaciones del estado. Considera importantes los presidios, sobre todo, el de Tucson, el más septentrional, la última de las poblaciones civilizadas de Sonora, que había sido blanco de sitios por "los enemigos" en varias ocasiones. El autor comparte su idea de que debido a las características y elementos que poseía el presidio señalado, "bajo los auspicios de una buena administración podría formarse no sólo una población de mucha consideración, sino otras muchas en un país tan feraz y tan pingüe en toda clase de producciones agrícolas". ${ }^{60}$

Velasco conocía la importancia de este pueblo como la frontera última del estado, sabía que podía ser una puerta para que entraran invasores o simplemente los bárbaros con sus constantes incursiones, por lo que consideraba que una solución ideal era la formación de varias poblaciones que explotaran los recursos naturales de la zona y, que al mismo tiempo, formaran una barrera contra los indios nómadas. No propuso ningún plan para el establecimiento de estas poblaciones, solamente mencionó la necesidad de las mismas.

Respecto al tema de la minería, Velasco señaló que para empezar a escribir acerca de esta temática le fueron de utilidad un informe del Barón de Humboldt (1771), los apuntes estadísticos de Juan Miguel Riesgo y Antonio José Valdés (1828) y las Noticias estadísticas de José Agustín de Escudero (1833). Considera que todas hablan de la importancia de la minería por las inmensas riquezas que encierra y que señalan las causas de su decadencia, pero ninguna se extendió en este ramo. Quizá por ello incluyó un capítulo detallado respecto a este tema. De hecho la obra de Velasco es, de entre las

${ }^{60}$ Ibid., 104-105. 
memorias estadísticas de la primera mitad del xIx, la única que trata de forma tan detallada el tema de la minería.

Asimismo es el tema minero un aspecto en el cual Francisco Velasco ve los efectos de la carencia de una estadística general de la entidad, al punto de señalar que es debido a esa omisión del gobierno, que el desarrollo de la minería fue afectado negativamente, ya que resintió el abandono y falta de protección de la administración pública. Las propuestas de nuestro autor para estimular la producción minera fueron las siguientes: el arreglo y protección de los puertos para regular la salida de los minerales en pasta; el abasto de azogue; el control del problema apache en el norte, para permitir la explotación de las minas localizadas en aquella zona; y el impulso a la minería por parte de hombres con espíritu de empresa. ${ }^{61}$

Velasco consideró que los problemas relacionados con la falta de impulso a la actividad minera eran la constante en el estado, relacionados estrechamente con la falta de constancia del gobierno que no sólo contribuyeron a la precaria existencia de los minerales, sino a que la población no hubiera aumentado como debiera. ${ }^{62}$ La idea de riqueza de un territorio estaba vinculada con el aumento constante del número de habitantes. La fertilidad de una región era considerada positiva y deseable, tanto en la producción de alimentos e insumos como en el aumento de la población. ${ }^{63}$

\section{Conclusiones}

Noticias estadísticas fue la obra principal de Velasco y tuvo en su época importancia indudable, fue publicada en 1850 en Sonora, posteriormente (1860) se publicó la mayor parte de ella en inglés, por la Universidad de California y finalmente apareció en partes en varios números del boletín de la SMGyE entre 1864 y 1865 . Cada una de las

${ }^{61}$ Ibid., 202.

${ }^{62}$ Idem.

${ }^{63}$ Laura Cházaro señala "Hasta bien entrado el siglo xIx predominará la idea -sostenida por los regímenes borbónicos- de que el crecimiento de la población expresa la riqueza, bondad y justicia del gobernante, que sus enfermedades los padecimientos de la república”. Laura Cházaro, "Imágenes de la población mexicana”, 17. 
publicaciones obedeció a diversos objetivos e intereses; en un primer momento la obra se elaboró y publicó cumpliendo con el interés principal del autor de que sirviera como información útil al gobierno del estado de Sonora, para una mejor administración pública, sobre todo, en los ramos militar, administración de justicia, elecciones y recaudación fiscal. La Universidad de California destacó, principalmente, la información relacionada con los grupos indígenas que habitaban el estado y la riqueza minera que estaba siendo desaprovechada. Finalmente, la SMgye publicó la obra al mismo tiempo que la consolidó, otorgándole reconocimiento de la comunidad científica nacional.

En el estado de Sonora, las Noticias estadisticas de Velasco sirvieron como modelo a los trabajos impulsados por el gobernador Ignacio Pesqueira en 1868 y 1878 . Se pedía a los prefectos de los distritos que elaboraran documentos periódicamente (se llegó a solicitar la información de forma mensual y anual) con el título precisamente de "noticias estadísticas", con información sobre el número de población del distrito, escuelas, prisiones, víveres, diversiones públicas, agricultura, fondo municipal y tranquilidad o paz pública. Con esta serie de datos se estaba siguiendo el modelo de los trabajos del tipo memorias o noticias estadísticas, al igual que se hizo en los informes que los gobernadores presentaban al congreso del estado para informar de los distintos ramos de su administración. Estos temas y esos trabajos eran considerados la estadistica estatal en ese momento, y serían superados a fines del siglo por los trabajos de la Dirección General de Estadística.

\section{BiBLIOGRAFÍA}

Almada, Francisco. Diccionario de historia, geografía y biografía sonorenses. Hermosillo: Gobierno de Estado de Sonora, 1983.

Annino, Antonio. "Nuevas perspectivas para una vieja pregunta". En El primer liberalismo mexicano, 1808-1855, coord. Marcela Fonseca, 43-91. México: InAH, Miguel Ángel Porrúa, 1995.

Самасно Оснод, José. "Humboldt y la historiografía mexicana”, Vuelo Libre (1) (octubre 2006): 39-50.

CAPEL, Horacio. Geografia y matemáticas en la España del siglo XVIII. Barcelona: OKIOS-TAU, 1982. 
Cházaro, Laura. "Imágenes de la población mexicana: descripciones, frecuencias y cálculos estadísticos", Relaciones Estudios de Historia y Sociedad XxiI(88) (otoño 2001): 15-48.

Desrosières, Alain. La política de los grandes números. Historia de la razón estadistica. Traducción del francés de Mónica Silvia Nasi. Santa Cruz de Tenerife: Editorial Melusina, 2004.

Donjuan Espinoza, Esperanza. "Las finanzas públicas en Sonora en la primera mitad del siglo xix. La cuestión fiscal”. En Memoria del Segundo Congreso de Historia Económica de México, 2004. http://www.economia.unam.mx/amhe/memoria (Fecha de consulta: 11 de septiembre de 2014).

- "Las penurias de la hacienda pública y las incursiones apaches en Sonora, 1830-1848". Ponencia presentada en el XVII Simposio de la Sociedad Sonorense de Historia, Hermosillo, 22 al 27 de noviembre, 2004.

Edin Cuadra, Dante. "Los enfoques de la geografía en su evolución como ciencia”. Revista Geográfica Digital (21) (enero-junio 2014): 1-22.

Enriquez Licón, Dora Elvia. Pocas flores, muchas espinas. Iglesia católica y sociedad en Sonora (1779-1912). México: Pearson, Universidad de Sonora, 2012.

Escudero, José Agustín de. Noticias estadísticas de Sonora y Sinaloa (1849). Hermosillo: Universidad de Sonora, 1997.

"Exposición dirigida al Sr. Benemérito de la patria general presidente D. Antonio López de Santa Anna, por el ciudadano Ignacio Zúñiga, representante suplente del mismo departamento". El siglo XIX, 27 de octubre de 1841.

Gaete Lagos, Jorge. "Reseña de Liberalismo y poder. Latinoamérica en el siglo XIX, ed. Iván Jacksik y Eduardo Posada Carbó”. Polis 10(30) (2011): 531-535.

Gamas Torruco, José. México y la constitución de Cádiz. México: Archivo General de la Nación, unAM, Museo de las Constituciones, 2012.

Hale, Charles A. El liberalismo mexicano en la época de Mora (18211853). México: Siglo XXI, 1972. 
Humboldt, Alejandro de. Ensayo político sobre el reino de la Nueva España. México: Editorial Porrúa, 1973.

INEGI. Catálogo de Documentos históricos de las estadísticas en México (siglos XVI-XIX). México: Instituto Nacional de Estadística, Geografía e Informática, 2005.

JAÚREGUI, Luis. "Los orígenes de un malestar crónico. Los ingresos y los gastos públicos en México. 1821-1855”. En Penuria sin fin, historia de los impuestos en México, siglos XVII-XX, coord. Luis Aboites y Luis Jaúregui, 79-114. México: Instituto de Investigaciones Dr. José María Luis Mora, 2005.

Krauze, Enrique. "Humboldt y México, un amor correspondido". Letras Libres (212) (julio 1994): 21-24.

Martínez de Lejarza, Juan José. Análisis estadístico de la Provincia de Michoacán en 1822. México: Imprenta Nacional del Supremo Gobierno de Estados Unidos Mexicanos, 1824.

MaYer Celis, Leticia. Entre el infierno de una realidad y el cielo de un imaginario. México: El Colegio de México, 1999.

Medina Bustos, José Marcos. "Vecinos, indios, vagos y sirvientes: avatares de la ciudadanía en Sonora durante la primera mitad del siglo XIX”. Región y Sociedad 14(25) (2002): 109-152.

. "Sonora, tierra en 'guerra viva': visiones sobre una sociedad de frontera (1822-1850). Un análisis historiográfico de cinco memorias estadísticas de la época de autores oriundos de la región". Tesis de Maestría en Historiografía de México, Universidad Autónoma Metropolitana, 1998.

Miguel, Ennid Gladys. "Enfoques, tendencias y Escuelas geográficas. De la geografía clásica o tradicional a los estudios culturales". Párrafos Geográficos (2) (2003): 1-6.

Mill, John Stuart. El utilitarismo. Traducción de Ramón Castilla. Buenos Aires: Aguilar, 1980.

OTERo, Hernán. Estadística y nación. Una historia conceptual del pensamiento censal de la Argentina moderna, 1869-1914. Buenos Aires: Prometeo Libros, 2006.

Peña, Sergio de la y James WiLkie. La estadística económica en México. Los orígenes. México: Siglo XXI Editores, UAM-Azcapotzalco, 1994. Pérez Ruiz, Maya Lorena. "Campesinos y nación. Reseña de $L a$ 
construcción de México y Perú poscoloniales, Florencia E. Mallon”. Alteridades (14) (enero-junio 2004).

Quiroz Moreno, Selene. "El cobro de la contribución directa ordinaria personal y la creación del catastro en Sonora. Primeros ensayos, 1857-1870”. Tesis de Maestría en Ciencias Sociales, El Colegio de Sonora, 2008.

Riesgo, Juan Miguel y Antonio José Valdés. Memoria estadística del Estado de Occidente (Guadalajara: Imprenta á cargo del C.E. Alatorre, 1828).

Thomson, Guy P. C. El liberalismo popular mexicano. Juan Francisco Lucas y la sierra de Puebla. 1864-1917. México: Ediciones de Educación y Cultura, Instituto de Ciencias Sociales y Humanidades "Alfonso Vélez Pliego", 2011.

Trejo, Zulema. "La época de Pesqueira: facciones, riqueza y poder. Sonora 1850-1876". Tesis de Maestría en Historia, El Colegio de Michoacán, 20 de septiembre de 2001.

. “Constituyentes y constitución. Sonora 1857-1861”. Historia Mexicana LIX(3) (enero-marzo 2010): 877-917.

Redes, facciones y liberalismo. Sonora, 1850-1876. Hermosillo: El Colegio de Sonora, 2012.

Trejo, Zulema y Esperanza Donjuan Espinoza. "Sonora y el proyecto liberal a través de las reflexiones de Ignacio Zúñiga”. En De los márgenes al centro. Sonora en la independencia y la revolución, cambios y continuidades, comp. Ignacio Almada Bay y José Marcos Medina Bustos, 155-182. Hermosillo: El Colegio de Sonora, Colegio de Bachilleres del Estado de Sonora, Colección 2010, 2011.

Velasco, José Francisco. Noticias Estadísticas del Estado de Sonora. Acompañadas de ligeras reflecsiones, deducidas de algunos documentos y conocimientos practicos adquiridos en muchos años, con fin de darlas al público y que los sabios Estadistas puedan hacer uso de las que les parezcan oportunas. México: Imprenta de Ignacio Cumplido, 1850.

. Sonora: its extent, population, natural production. Indian tribes, mines, mineral, land, etc.,etc. San Francisco: H. H. Bancroft and Company, 1861. 
. Noticias estadísticas del estado de Sonora. Hermosillo: Gobierno del Estado de Sonora, 1985.

ZúNiga, Ignacio. Rápida ojeada al estado de Sonora (1835). Hermosillo: Gobierno del Estado de Sonora, 1983.

WorDCAT. http://www.worldcat.org/title/noticias-estadisticas-delestado-de-sonora/oclc/760449270/editions? referer=di\&edition sView=true [Sin año de publicación] (Fecha de consulta: 7 de septiembre de 2014). 